\title{
Physicochemical characterization and aerosol dispersion performance of organic solution advanced spray-dried cyclosporine A multifunctional particles for dry powder inhalation aerosol delivery
}

\author{
This article was published in the following Dove Press journal: \\ International Journal of Nanomedicine \\ 23 March 2013 \\ Number of times this article has been viewed
}

\begin{abstract}
Xiao $\mathrm{Wu}^{\prime}$
Weifen Zhang ${ }^{1,2}$

Don Hayes J $\mathrm{r}^{3-5}$

Heidi M Mansour ${ }^{1,6}$

'Department of Pharmaceutical Sciences - Drug Development Division, University of Kentucky, Lexington, KY, USA; ${ }^{2}$ College of Pharmacy and Biological Science, Weifang Medical University, Weifang, People's Republic of China; ${ }^{3}$ Department of Pediatrics, ${ }^{4}$ Department of Internal Medicine, The Ohio State University College of Medicine, Nationwide Children's Hospital Lung and Heart-Lung Transplant Program, ${ }^{5}$ Davis Heart and Lung Research Institute, The Ohio State University, Columbus, $\mathrm{OH},{ }^{6} \mathrm{C}$ enter of Membrane Sciences, University of Kentucky, Lexington, KY, USA
\end{abstract}

\begin{abstract}
In this systematic and comprehensive study, inhalation powders of the polypeptide immunosuppressant drug - cyclosporine A - for lung delivery as dry powder inhalers (DPIs) were successfully designed, developed, and optimized. Several spray drying pump rates were rationally chosen. Comprehensive physicochemical characterization and imaging was carried out using scanning electron microscopy, hot-stage microscopy, differential scanning calorimetry, powder X-ray diffraction, Karl Fischer titration, laser size diffraction, and gravimetric vapor sorption. Aerosol dispersion performance was conducted using a next generation impactor with a Food and Drug Administration-approved DPI device. These DPIs displayed excellent aerosol dispersion performance with high values in emitted dose, respirable fraction, and fine particle fraction. In addition, novel multifunctional inhalation aerosol powder formulations of cyclosporine A with lung surfactant-mimic phospholipids were also successfully designed and developed by advanced organic solution cospray drying in closed mode. The lung surfactantmimic phospholipids were 1,2-dipalmitoyl-sn-glycero-3-phosphocholine and 1,2-dipalmitoyl-snglycero-3-(phosphor-rac-1-glycerol). These cyclosporine A lung surfactant-mimic aerosol powder formulations were comprehensively characterized. Powder X-ray diffraction and differential scanning calorimetry confirmed that the phospholipid bilayer structure in the solid state was preserved following advanced organic solution spray drying in closed mode. These novel multifunctional inhalation powders were optimized for DPI delivery with excellent aerosol dispersion performance and high aerosol performance parameters.
\end{abstract}

Keywords: dry powder inhaler(DPI), polypeptide drug, lung surfactant, calcineurin inhibitor, lung immunosuppression, dipalmitoylphosphatidylcholine (DPPC), dipalmitoylphosphatidylglycerol (DPPG), targeted lung immunosuppression

\section{Introduction}

Cyclosporine A (CsA) is a lipophilic (hydrophobic), cyclic undecapeptide, and a high molecular weight polypeptide immunosuppressant drug. ${ }^{1-3}$ As a calcineurin inhibitor, CsA reversibly inhibits T-cell mediated immune response, including the synthesis of interleukin-2, interleukin-6, and interferon- $\gamma{ }^{3}$ As a calcineurin inhibitor, it blocks lymphocyte activation by inhibiting transcription of cytokine genes in a dose-dependent manner. ${ }^{1-3}$ In addition, CsA has therapeutic effects on the prevention of allograft rejection after lung transplantation. ${ }^{4,5}$ The systemic effects associated with CsA are substantial, including hypertension and most notably renal toxicity. ${ }^{6}$ Local noninvasive administration of CsA as aerosols may reduce the incidence of toxic complications associated with
Correspondence: Heidi M Mansour University of Kentucky, College of Pharmacy, Department of Pharmaceutical Sciences - Drug Development Division, 789 S Limestone Street, Lexington, KY 40536-0596, USA

Tel + I 859257 I57|

Fax +l 8592577564

Email heidi.mansour@uky.edu 
systemic administration of CsA, increase the therapeutic availability of CsA for localized immunosuppression, and provide a high pulmonary concentration. ${ }^{7-9}$ Local pulmonary delivery of CsA as nebulized liquid aerosols in lung transplant patients has been reported. ${ }^{10,11}$ The improved response in a lung transplant patient by inhaled nebulized tacrolimus, another important immunosuppressant drug, for successful lung immunosuppression while significantly reducing systemic side effects and improving patient outcomes has been recently reported by the authors' group. ${ }^{12}$ A metered-dose inhaler of CsA has been aerosolized in asthmatic patients. ${ }^{8} \mathrm{~A}$ nebulized liquid aerosol of CsA encapsulated in liposomes composed of nonionic surfactants and phospholipids, ${ }^{13}$ inhaled CsA dry powders produced by wet-milling, ${ }^{14}$ and inhaled CsA inulin-based dry powders produced by spray freeze drying from a tert-butyl alcohol/water cosolvent system ${ }^{15}$ have been reported. Recently, CsA nanosuspensions containing mannitol (ie, a water-soluble sugar) produced by antisolvent precipitation followed by aqueous solution spray drying (SD) generated inhalable CsA mannitol powders. ${ }^{16}$ In addition, evaporative precipitation into aqueous solution has been reported to produce CsA nanoparticles possessing low crystallinity for oral and/or parenteral delivery with enhanced bioavailability resulting from high dissolution rates. ${ }^{17}$

Dry powder inhalers (DPIs) of CsA are a targeted delivery option for direct administration of CsA to the lung. Targeted delivery of a wide array of pulmonary drugs directly and efficiently to the lungs has been reported, ${ }^{12,18-21}$ and with high patient acceptance. DPIs offer many advantages such as improved stability, higher dose delivery, and better control of aerosol particle properties. ${ }^{19,22-25}$ Performance of inhaled aerosols are influenced by the physicochemical properties of the inhaled particles including particle size, size distribution, particle morphology, surface morphology, and residual water content. ${ }^{19,22-24,26}$ Inhaled particles with a particle size in the range of $400 \mathrm{~nm}$ to $5 \mu \mathrm{m}$ can efficiently target the smaller airways and deep lung regions. ${ }^{19,20,22,23,27}$

Pulmonary surfactant is secreted by the type II pneumocytes in the lining of the alveoli. It is comprised of a mixture of specific phospholipids and lung surfactant-specific proteins. It has a vital role in reducing the work of breathing by reducing the surface tension to near $0 \mathrm{mN} / \mathrm{m}$ at the air/ water interface in the lung. ${ }^{28-31}$ The main constituents of pulmonary surfactant are lipids and lung surfactant-specific proteins, which account for $\sim 90 \%$ and $10 \%$ of the surfactant mass, respectively. ${ }^{32,33}$ Of the lipids, $\sim 85 \%-90 \%$ are specific phospholipids, of which $\sim 80 \%$ are phosphatidylcholine and $\sim 10 \%$ are phosphatidylglycerol. ${ }^{28,30,33}$ The fraction of phosphatidylcholine accounted for by dipalmitoylphosphatidylcholine (DPPC), a disaturated 16-carbon acyl chain phosphatidylcholine, is $54 \%$ in humans. ${ }^{34}$ The lung surfactant-mimic phospholipids - DPPC and dipalmitoylphosphatidylglycerol (DPPG) - are used in lung surfactant replacement therapies, controlled release drug delivery, liposomal drug delivery, and phospholipid colloidal carrier nanomedicine pulmonary delivery. ${ }^{25,27,30,35-38}$ Novel DPIs containing phospholipids as multifunctional biocompatible excipients offer several unique advantages, as described in detail by the authors' group. ${ }^{25}$ It has been demonstrated that phospholipids improve migration of particles to the lung periphery by spreading due to the reduction in surface tension provided by their surface chemistry. ${ }^{27-30,35,39} \mathrm{DPPC}$ and DPPG phospholipids are innate to the lung, and hence are inherently biocompatible and biodegradable in the lung. These phospholipids may also facilitate drug absorption by improving wettability. In nanopharmaceuticals, phospholipids self-assemble to form colloidal nanocarriers. ${ }^{27,35-38}$ Novel DPIs for pulmonary nanomedicine delivery composed of respirable microparticulate/nanoparticulate dry powders of DPPC/poly(ethylene glycol) (PEG)ylated phospholipid systems ${ }^{40}$ and tacrolimus inhalation powders ${ }^{41}$ have been recently reported by the authors' group. Respiratory delivery of CsA incorporated in biocompatible biodegradable lung surfactant-mimic DPPC/DPPG in the solid state as DPI aerosols would facilitate CsA delivery, with high local concentration in the smaller airways of the lung.

This systematic and comprehensive study reports for the first time the rational design, physicochemical characterization, and optimization of novel therapeutic aerosols as DPIs of respirable CsA microparticles and nanoparticles for targeted DPI delivery for lung transplant immunosuppression. The novel engineering high-throughput process of organic solution advanced SD in closed mode was employed, as reported by the authors for the first time for pulmonary delivery inhalation applications. ${ }^{40-42}$ In addition, this study reports for the first time the rational design, physicochemical characterization, and high-throughput optimization of novel DPIs consisting of CsA with lung surfactant-mimic DPPC/DPPG phospholipids as dry powder microparticulate/ nanoparticulate aerosols designed by advanced organic solution co-SD in closed mode.

\section{Material and methods Materials}

CsA US Pharmacopeia grade (Spectrum Chemical Mfg Corp, New Brunswick, NJ, USA) has a molecular weight of 
$1202.61 \mathrm{~g} / \mathrm{mol}$. Methanol (high-performance liquid chromatography grade, American Chemical Society certified, $0.2 \mu \mathrm{m}$ filtered) was used for all SD experiments and was purchased from Thermo Fisher Scientific (Waltham, MA, USA). Synthetic lung surfactant-mimic phospholipid powders, 1,2-dipalmitoyl-sn-glycero-3-phosphocholine (ie, DPPC) and 1,2-dipalmitoyl-sn-glycero-3-(phosphor-rac-1-glycerol) sodium salt (ie, DPPG), were purchased from Avanti Polar Lipids Inc (Alabaster, AL, USA). AQUASTAR ${ }^{\circledR}$ anhydrous methanol $99.8 \%$ was obtained by EMD Chemicals, Inc (Darmstadt, Germany). Hydranal ${ }^{\circledR}$-Coulomat AD was from Sigma-Aldrich (St Louis, MO, USA). All powders were stored in tightly sealed glass desiccators over Drierite ${ }^{\mathbb{R}} /$ Indicating Drierite ${ }^{\circledR}$ (W A Hammond Drierite Co, Ltd, Xenia, $\mathrm{OH}, \mathrm{USA})$ desiccant in the freezer at $-23^{\circ} \mathrm{C}$.

\section{Preparation of SD CsA and co-SD CsA: DPPC/DPPG particles from organic solution advanced SD in closed mode}

Solutions containing CsA were prepared with a total powder mass of $1 \%$ (weight/volume) in methanol. The prepared formulations were subsequently SD using the Buchi mini SD B-290 with a Buchi high-performance cyclone plus the Buchi inert loop B-295 (Buchi Labortechnik AG, Flawil, Switzerland) in closed mode under ultra high purity (UHP) nitrogen gas (Scott-Gross Company, Inc, Winchester, KY, USA). As stated in Table 1 and similar to the advanced SD conditions previously reported by the current authors, ${ }^{40,42}$ the following SD conditions in closed mode were used: inlet temperature, $100^{\circ} \mathrm{C}$; UHP nitrogen atomizing gas flow $601 \mathrm{~L} /$ hour; various pump rates rationally selected; and aspirator setting, $100 \%$. The four SD pump rates were rationally chosen at 10\% (low), 25\%, 50\% (medium), and 75\% (high).

Co-SD CsA powders of CsA lung surfactant lipospheres were prepared by dissolving DPPC, DPPG, and the drug simultaneously in methanol with a total powder mass of $1 \%$

Table I Spray drying parameters of four pump rates, inlet temperature, and the corresponding outlet temperature in the spray drying process of dilute organic solution advanced spraydried cyclosporine A dry powder inhalers

\begin{tabular}{llll}
\hline Sample & $\begin{array}{l}\text { Pump } \\
\text { rate, } \%\end{array}$ & $\begin{array}{l}\text { Inlet } \\
\text { temperature, }{ }^{\circ} \mathbf{C}\end{array}$ & $\begin{array}{l}\text { Outlet } \\
\text { temperature, }{ }^{\circ} \mathbf{C}\end{array}$ \\
\hline SD CsA 10\%P & 10 & 100 & 53 \\
SD CsA 25\%P & 25 & 100 & 43 \\
SD CsA 50\%P & 50 & 100 & 30 \\
SD CsA 75\%P & 75 & 100 & 22 \\
\hline
\end{tabular}

Abbreviations: \%P, pump rate; CsA, cyclosporine A; SD, spray dried. $(\mathrm{w} / \mathrm{v})$ followed by co-SD under optimized SD conditions (50\% pump rate). The molar ratio of DPPC:DPPG was 3:1, as this is a lung surfactant-mimic ratio. The advanced co-SD process was operated under the conditions described above. All SD and co-SD powders were stored in a desiccator in the freezer until analysis.

\section{Laser diffraction particle size and size distribution}

Using similar conditions as previously reported, ${ }^{42-45}$ the primary particle size in the solid state and size distribution were measured by an ultraviolet laser diffraction nanoparticle size analyzer (SALD-7101; Shimadzu Corporation, Kyoto, Japan). The measured sample was prepared by dispersing $40 \mathrm{mg}$ powder in $10 \mathrm{~mL}$ deionized water in a capped vessel and then gently shaking. Prior to each measurement, background measurements were carried out by using a blank cell filled with deionized water. Then, $1.5 \mathrm{~mL}$ of the sample was added to the blank for measurement. The refractive index of the measured samples was $1.60-0.10$.

\section{Scanning electron microscopy (SEM)}

Using similar conditions as previously reported, ${ }^{40,42-45}$ the shape and surface morphology of all raw, SD, and co-SD powders were investigated by SEM (S-800; Hitachi Ltd, Tokyo, Japan). Each sample was fixed on an aluminum specimen stub covered with a double-sided adhesive carbon disc, and then sputter coated (Hummer VI Sputtering System; Technics, Anatech USA, Union City, CA, USA) with gold prior to imaging. Sputter coating was performed at $20 \mathrm{~mA}$ for 3 minutes.

\section{Differential scanning calorimetry (DSC)}

Using similar conditions as previously reported, ${ }^{28-30,40,42-46}$ DSC was performed by using model Q200TM equipped with an automated computer-controlled refrigerated cooling system (RSC-90) and Tzero ${ }^{\mathrm{TM}}$ capabilities (TA Instruments, New Castle, DE, USA). The DSC thermograms were collected using a sample weight of 3-5 $\mathrm{mg}$ powder and placed in Tzero alodine-coated aluminum DSC pans, which were then hermetically sealed with a Tzero hermetic sealer (TA Instruments). The phase transition temperatures - melting point $\left(\mathrm{T}_{\mathrm{m}}\right)$ - of the samples were measured under a $50 \mathrm{~mL} /$ minute dry UHP nitrogen gas (Scott-Gross) purge in DSC. The samples were heated at $5^{\circ} \mathrm{C} /$ minute from $10^{\circ} \mathrm{C}$ to $300^{\circ} \mathrm{C}$. At least four melting scans were carried out to ensure $\mathrm{T}_{\mathrm{m}}$ reproducibility. The measured DSC data were analyzed using a coupled DSC Q200-1740 data station (TA Instruments). 


\section{X-ray powder diffraction (XRPD)}

Using similar conditions as previously reported, ${ }^{30,40,42-45}$ the degree of long-range molecular order (crystallinity) versus disorder (noncrystallinity) for all powders was measured by XRPD. The XRPD pattern was collected with a Rigaku Multiflex X-ray diffractometer (Rigaku Corporation, Tokyo, Japan) with a slit detector copper $\mathrm{K} \alpha$ source at $44 \mathrm{~mA}$ and $40 \mathrm{kV}$. CsA samples were gently pressed onto a glass slide (Rigaku) to form a level surface. The glass slide was then placed in the X-ray beam path. Data were obtained from 5-60 $2 \theta$ degrees at room temperature at a scanning rate of $22 \theta$ degrees/minute and a step rate of $0.042 \theta$ degrees.

\section{Cross-polarizing light hot-stage microscopy} Using similar conditions as previously reported, ${ }^{40,42}$ solid-state phase transitions for raw CsA, SD CsA, and co-SD CsA lung surfactant-mimic phospholipid powders were observed under cross-polarizing light hot-stage microscopy (HFM) for the presence and/or absence of birefringency. The polarized optical microscope (BX51; Olympus Corporation, Tokyo, Japan) and a hot stage were equipped with a temperature control unit (STC200; Instec Inc, Boulder, CO, USA). The microscope was connected to a computer and SPOT Advanced ${ }^{\mathrm{TM}}$ software (Diagnostic Instruments, Inc, Sterling Heights, MI, USA) was used to capture pictures from the microscope. The temperature control unit was also connected to a computer and WinTemp 2.00 software (Instec Inc., Boulder, CO, USA) was used to set up the heating conditions. Samples were mounted on a microscope glass slide and placed into the sample chamber of the hot stage. Samples were then heated from $25^{\circ} \mathrm{C}$ to a final temperature of $200^{\circ} \mathrm{C}$ at a step rate of $5^{\circ} \mathrm{C} /$ minute.

\section{Circular dichroism (CD) spectroscopy}

Using similar conditions as previously reported, ${ }^{30} \mathrm{CD}$ measurements were carried out on model J-810 Spectropolarimeter (Jasco, Inc, Easton, MD, USA). CsA was dissolved in methanol at a concentration of $100 \mu \mathrm{M}$. The scanning wavelength range was $195-250 \mathrm{~nm}$ in $0.5 \mathrm{~nm}$ increments. Nitrogen gas was supplied to prevent the accumulation of oxygen in the system, which produces CD absorption bands around $200 \mathrm{~nm}$. Other parameters were the following: data pitch: $0.5 \mathrm{~nm}$; scan speed: $50 \mathrm{~nm} /$ minute; response time: 8 seconds; accumulation: four; and band width: $1 \mathrm{~nm}$. The baseline spectrum of the solvent alone was taken prior to sample measurements.

\section{Karl Fischer coulometric titration}

Using similar conditions as previously reported, ${ }^{40,42,46}$ residual water content in the DPI aerosol powders was analytically quantified by Karl Fischer coulometric titration method using a Karl Fischer titrator cell (737 KF Coulometer; Metrohm AG, Herisau, Switzerland) equipped with a magnetic stirring device (703 Ti Stand; Metrohm). Karl Fischer titrator was filled with Hydranal-Coulomat AD reagent, comprising of methanol, diethanolamine, imidazole, hydroiodic acid, and sulfur dioxide. The powder sample was prepared by dissolving $50 \mathrm{mg}$ of powder into $100 \mathrm{~mL}$ AQUASTAR anhydrous methanol. The precisely weighed sample solution $(\sim 500 \mathrm{mg})$ was then injected into Karl Fischer titrator to react with titration reagent under magnetic stirring. At the end point of titration, the water amount in the analyzed CsA sample was displayed automatically on the titrator. Given that the weight of reacted sample was known, the percentage of water in the sample was calculated.

\section{Gravimetric water vapor sorption}

Using similar conditions as previously reported, ${ }^{30,42,46}$ gravimetric water vapor isotherms were measured using a Cahn ${ }^{\circledR}$ automated ultrasensitive microelectronic balance coupled to a computerized SGA-CX Symmetrical Gravimetric Analyzer (VTI Corporation, Hialeah, FL, USA) under dry UHP nitrogen gas vacuum conditions. All measurements were made at $25^{\circ} \mathrm{C}$ using a sample size of $1.5-2.5 \mathrm{mg}$. Before the absorption step, samples were dried in situ under dry UHP nitrogen gas vacuum conditions. The criterion used to establish drying equilibrium was a weight change of $0 \%$ in a 10 -minute interval. At the end of the drying cycle, the sample was exposed to a sequence of increasing relative humidity $(\mathrm{RH})$ levels under equilibrium conditions starting at $0 \% \mathrm{RH}$. Data were logged every 2 minutes or when weight gain reached $0.01 \%$. Up to a maximum of 3 hours was allowed, which was sufficient to reach absorption equilibrium at each RH level. The criterion used to establish absorption equilibrium was a weight change of $\leq 0.03 \%$ in a 10 -minute interval.

\section{In vitro aerosol dispersion performance by the next generation impactor (NGI)}

The US Pharmacopeia describes the specifications on aerosols performance ${ }^{47}$ and, as previously reported, ${ }^{40}$ the aerosol dispersion performance was tested using inertial impaction. The aerosol dispersion properties of the dry powder particles as DPIs were determined using the NGI with a stainless steel induction port (ie, US Pharmacopeia throat) attachment (170 NGI ${ }^{\mathrm{TM}}$; MSP Corporation, Shoreview, MN, USA), equipped with specialized stainless steel NGI gravimetric insert cups (MSP Corporation). A DFM 2000 flow meter (Copley Scientific, Nottingham, UK) was employed to measure and adjust the airflow rate (Q) prior to each experiment. 
The NGI was coupled with a TPK 2000 critical flow controller (Copley) that was connected to an HCP5 vacuum pump (Copley). The NGI was operated at a controlled flow rate of $\mathrm{Q}=60 \mathrm{~L} /$ minute. For the NGI Q $=60 \mathrm{~L} /$ minute, the effective cutoff diameters for each impactor stage were calibrated by the manufacturer and stated as follows: stage one $(8.06 \mu \mathrm{m})$; stage two $(4.46 \mu \mathrm{m})$; stage three $(2.82 \mu \mathrm{m})$; stage four $(1.66 \mu \mathrm{m})$; stage five $(0.94 \mu \mathrm{m})$; stage six $(0.55 \mu \mathrm{m})$; and stage seven (0.34 $\mu \mathrm{m})$.

The aerosolization studies were experimentally designed by Design-Expert ${ }^{\circledR}$ 8.0.7.1 software (Stat-Ease, Inc, Minneapolis, MN, USA). Glass fiber filters (Type A/E, $55 \mathrm{~mm}$; Pall Corporation, Port Washington, NY, USA) were placed in the stainless steel NGI gravimetric insert cups for NGI stages one through seven to minimize bounce or reentrapment. Three hydroxypropyl methylcellulose hard capsules (size three, Quali-V ${ }^{\circledR}$; Qualicaps, Irving, TX, USA) were each loaded with $10 \mathrm{mg}$ powder, which were then loaded into a high resistance (ie, high sheer stress) human DPI device (HandiHaler ${ }^{\circledR}$; Boehringer Ingelheim $\mathrm{GmbH}$, Ingelheim, Germany), and tightly inserted into the induction port. Three capsules (containing $10 \mathrm{mg}$ of aerosol formulation per capsule) were used per aerosol experiment run. For each aerosol experiment run, the mass of particles deposited onto each stage was determined gravimetrically by measuring the difference in mass of the glass filters after particle deposition.

The mass mean aerodynamic diameter (MMAD) and geometric standard deviation (GSD) were calculated using a mathematic program written by Dr Jay Holt. ${ }^{48}$ All experiments were triplicated $(n=3)$. The fine particle dose, fine particle fraction (FPF), respirable fraction (RF), and emitted dose (ED) were calculated as follows:

Fine particle dose $=$ Mass of particles $<4.46 \mu \mathrm{m}$ (stages two through seven)

$\mathrm{FPF}=\frac{\text { Fine particle dose }}{\text { Initial particle mass loaded into capsules }} \times 100 \%$

$$
\begin{aligned}
& \mathrm{RF} \\
& =\frac{\text { mass of particles }<448 \mu \mathrm{m} \text { (stages two through seven) }}{\text { total particle mass on all stages }}
\end{aligned}
$$

ED

$$
\begin{aligned}
= & \frac{\text { Initial mass in capsules }- \text { Final mass remaining in capsules }}{\text { Initial mass in capsules }} \\
& \times 100 \%
\end{aligned}
$$

\section{Data and statistical analyses}

The results were analyzed statistically using Prism ${ }^{\circledR} 4$ software (GraphPad Software, Inc, La Jolla, CA, USA). The results are expressed as mean \pm standard deviation. An unpaired Student's $t$-test and one-way analysis of variance were used to compare the means and to assess statistical significance. Results were considered statistically significant if $P<0.001$. The aerosolization studies were experimentally designed using design of experiments by Design-Expert 8.0.7.1 software (Stat-Ease).

\section{Results \\ Laser diffraction particle size and size distribution}

Table 1 provides a summary of the CsA samples investigated in the current study. During the SD process, when the operating parameters - including nozzle orifice, atomization pressure, feed solvent, feed concentration, inlet temperature, and spray gas flow rate remained constant - different pump rates resulted in different outlet temperatures, which is to be expected (Table 1).

In laser diffraction analysis of SD CsA at rationally chosen pump rates (Table 2 ), the $\mathrm{Dv}_{10}$ volumetric particle size range over the range of pump rates was $0.81-1.16 \mu \mathrm{m}$, the $\mathrm{Dv}_{50}$ volumetric particle size range over the range of pump rates was $0.95-1.41 \mu \mathrm{m}$, and the $\mathrm{Dv}_{90}$ volumetric particle size range over the range of pump rates was $2.91-3.79 \mu \mathrm{m}$. A correlation was observed in which increasing the SD pump rate of drug organic solution yields particles with a slightly larger particle size. The particle size distribution for the SD CsA aerosol powders was unimodal and narrow, which is important for enhancing reproducible aerosol delivery.

Table 3 lists the compositions of co-SD CsA lung surfactant-mimic liposphere aerosol powder formulations designed in this study. In laser diffraction analysis, the mean $\mathrm{Dv}_{50}$ sizes of co-SD CsA:DPPC/DPPG 25:75 and co-SD CsA:DPPC/DPPG 75:25 were $1.49 \mu \mathrm{m}$ and $1.73 \mu \mathrm{m}$, respectively (Table 3 ). The particle size distribution of the co-SD CsA:DPPC/DPPG lung surfactant-mimic particles was unimodal and narrow, which is important for reproducible aerosol delivery.

\section{SEM}

The particle morphology, surface morphology, and primary particle size of raw unprocessed CsA and SD CsA DPI aerosol formulations were imaged and the SEM micrographs are shown 
Table 2 Volumetric particle size $\left(\mathrm{Dv}_{10}, \mathrm{Dv}_{50}\right.$, and $\left.\mathrm{Dv} \mathrm{v}_{90}\right)$, particle shape, and surface morphology properties of spray-dried cyclosporine $\mathrm{A}$ dry powder inhalation powders from different pump rates

\begin{tabular}{|c|c|c|c|c|c|}
\hline Sample & $\begin{array}{l}\text { Volumetric particle } \\
\text { size } D v_{10}, \mu \mathrm{m}\end{array}$ & $\begin{array}{l}\text { Volumetric particle } \\
\text { size } \mathrm{Dv}_{50}, \mu \mathrm{m}\end{array}$ & $\begin{array}{l}\text { Volumetric particle } \\
\text { size } D v_{90}, \mu \mathrm{m}\end{array}$ & $\begin{array}{l}\text { Particle } \\
\text { shape }\end{array}$ & $\begin{array}{l}\text { Surface } \\
\text { morphology }\end{array}$ \\
\hline SD CsA $10 \% \mathrm{P}$ & $0.81 \pm 0.03$ & $0.95 \pm 0.09$ & $2.91 \pm 0.18$ & Sphere & Corrugated \\
\hline SD CsA 25\%P & $0.94 \pm 0.04$ & $1.12 \pm 0.08$ & $3.10 \pm 0.22$ & Sphere & Corrugated \\
\hline SD CsA 50\%P & $0.99 \pm 0.01$ & $1.33 \pm 0.10$ & $3.47 \pm 0.15$ & Sphere & Corrugated \\
\hline SD CsA 75\%P & $1.16 \pm 0.03$ & $1.41 \pm 0.08$ & $3.79 \pm 0.31$ & Sphere & Smooth \\
\hline
\end{tabular}

Notes: Mean \pm standard deviation, $n=5$.

Abbreviations: \% , pump rate; CsA, cyclosporine A; SD, spray dried.

in Figure 1. As can be seen, the raw CsA are too large for inhalation with irregular nonspherical morphology (Figure 1A). SD CsA aerosol powders prepared at 10\% (Figure 1B), 25\% (Figure 1C), and 50\% (Figure 1D) pump rates are observed as spherical particles with a corrugated surface, while SD CsA at a $75 \%$ pump rate (Figure 1E) is observed as spherical particles with a smooth surface. Particle dimensions of all SD batches appear much smaller than that of raw CsA and are in excellent agreement with those measured by laser diffraction particle sizing (Table 2). The particle morphology and surface morphology are summarized in Table 2.

The SEM micrograph of raw CsA and co-SD CsA lung surfactant-mimic lipospheres are shown in Figure 2. The raw unprocessed CsA (Figure 2A) have an irregular nonspherical morphology with very large dimensions that are much too large for inhalation. The co-SD CsA lung surfactant-mimic liposphere particles (Figures 2B and C) appear as spherical particles with a smooth surface morphology. The particle size of co-SD CsA:DPPC/DPPG lung surfactant-mimic particles observed in their SEM images is in excellent agreement with that measured by laser diffraction particle sizing (Table 3) and much smaller than that of raw CsA, making them within the inhalable size range for targeted pulmonary delivery as DPIs.

\section{DSC}

The DSC thermograms of raw CsA versus SD CsA aerosol powders are shown in Figure 3. Raw CsA was characterized by a sharp narrow endothermic phase transition peak, which had an onset temperature at $\sim 161^{\circ} \mathrm{C}$. The melting of crystalline CsA is similar to that reported in the literature. ${ }^{49,50}$ This order-to-disorder endothermic peak can be attributed to melting. These observations are in good agreement with previous reports on crystalline $\mathrm{CsA}$, indicating the crystalline nature of the raw drug. Similarly, the thermograms of SD CsA aerosol powders at a $10 \%, 25 \%, 50 \%$, and $75 \%$ pump rate showed endothermic peaks with onset temperatures of $\sim 152^{\circ} \mathrm{C}, 162^{\circ} \mathrm{C}, 153^{\circ} \mathrm{C}$, and $154^{\circ} \mathrm{C}$, respectively. The peaks that represent the SD samples correspond to those of the original CsA but differ in intensity (peak broadness), suggesting that the SD process has rendered the final powder in a different state from the raw as is often observed in SD.

The thermograms of raw CsA and co-SD aerosol powder formulations are shown in Figure 4. DPPC powders exhibited two endothermic phase transitions at $66.9^{\circ} \mathrm{C}$ and $73.0^{\circ} \mathrm{C}$, corresponding to the gel-to-ripple bilayer pretransition and to the bilayer main transition $\mathrm{T}_{\mathrm{m}}$ (ie, due to the hydrophobic acyl chain melting event) between the rippled gel and liquid crystalline phases, respectively. ${ }^{46}$ DPPG powders showed three endothermic phase transitions consisting of two lowenthalpy pretransitions at $\sim 55.3^{\circ} \mathrm{C}$ and $\sim 79.5^{\circ} \mathrm{C}$ and a highenthalpy main phase transition at $125^{\circ} \mathrm{C}$, which correspond to the crystal-to-gel bilayer phase transition, gel-to-ripple bilayer phase transition, and rippled-to-liquid crystalline bilayer main phase transition $\left(\mathrm{T}_{\mathrm{m}}\right)$, respectively. ${ }^{46} \mathrm{Co}-\mathrm{SD}$ aerosol powder formulations of co-SD CsA:DPPC/DPPG

Table 3 Compositions and average volumetric particle size $\left(\mathrm{Dv}_{50}\right)$ of cospray-dried cyclosporine A: dipalmitoylphosphatidylcholine/ dipalmitoylphosphatidylglycerol lung surfactant-mimic dry powder inhalation aerosol formulations by advanced cospray drying from organic solution

\begin{tabular}{llll}
\hline co-SD CsA: (DPPC/DPPG) & $\begin{array}{l}\text { CsA content, } \\
\text { mole } \%\end{array}$ & $\begin{array}{l}\text { Phospholipid (DPPC/DPPG) } \\
\text { content, mole \% }\end{array}$ & $\begin{array}{l}\text { Volumetric particle } \\
\text { size, }\end{array}$ \\
\hline co-SD CsA lipo $25: 75(1: 3)$ & 25 & 75 & $1.49 \pm 0.16$ \\
co-SD CsA lipo 75:25 (3:1) & 75 & 25 & $1.73 \pm 0.08$ \\
\hline
\end{tabular}

Notes: Mean \pm standard deviation, $n=5$.

Abbreviations: CsA, cyclosporine A; DPPC, dipalmitoylphosphatidylcholine; DPPG, dipalmitoylphosphatidylglycerol; lipo, lipospheres; SD, spray dried. 

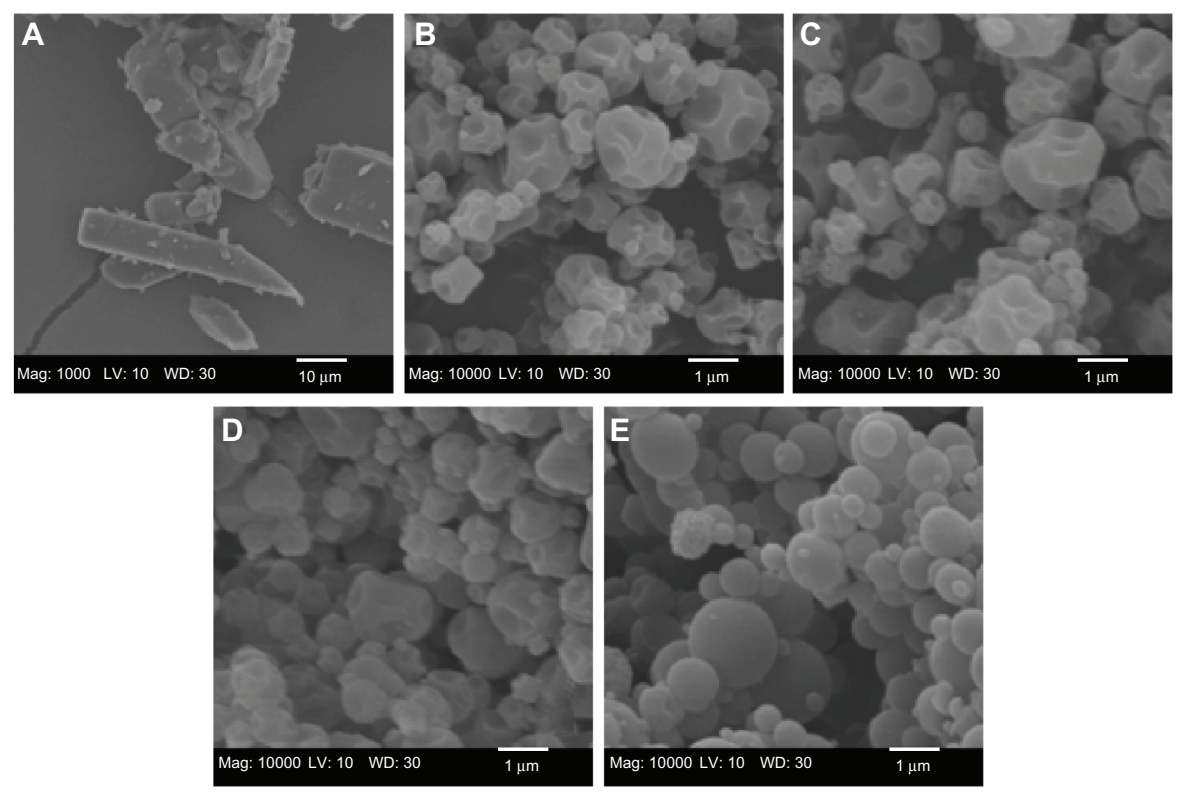

Figure I Representative scanning electron micrographs of (A) raw unprocessed cyclosporine A and spray-dried cyclosporine A at a (B) $10 \%$ pump rate; (C) $25 \%$ pump rate; (D) $50 \%$ pump rate; and (E) $75 \%$ pump rate.
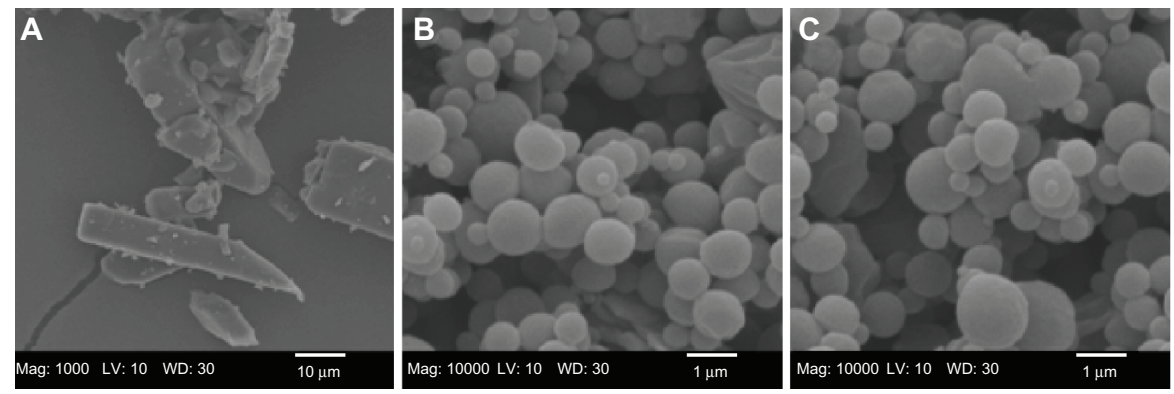

Figure 2 Representative scanning electron micrographs of (A) raw unprocessed cyclosporine A and cospray-dried cyclosporine A: dipalmitoylphosphatidylcholine/ dipalmitoylphosphatidylglycerol ratio of (B) 25:75 (I:3) and (C) 75:25 (3:I).

Abbreviations: CsA, cyclosporine A; DPPC, dipalmitoylphosphatidylcholine; DPPG, dipalmitoylphosphatidylglycerol; SD, spray dried.

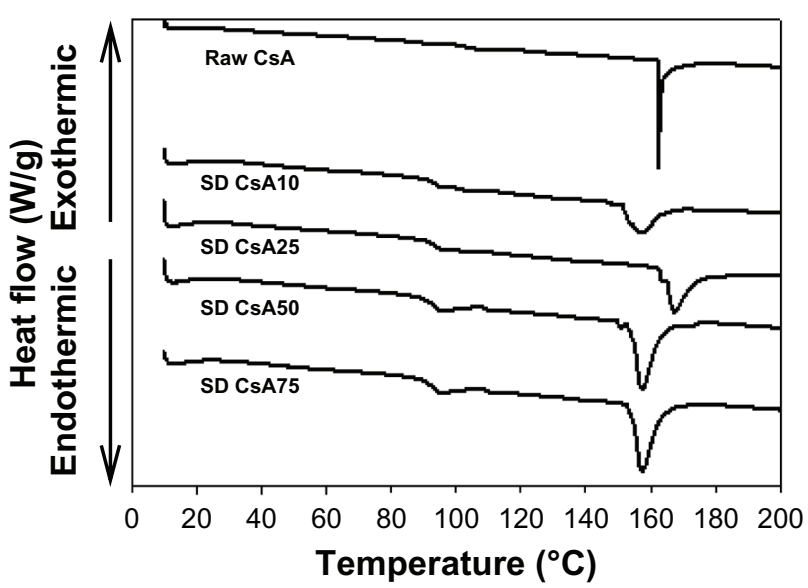

Figure 3 Representative differential scanning calorimetry thermograms at $5^{\circ} \mathrm{C} /$ minute heating scan rate of raw $\mathrm{CsA}$ and organic solution advanced SD CsA dry powder inhalation aerosol powders.

Notes: $10,25,50$, and 75 indicate a pump rate of $10 \%, 25 \%, 50 \%$, and $75 \%$, respectively.

Abbreviations: CsA, cyclosporine A; SD, spray dried.

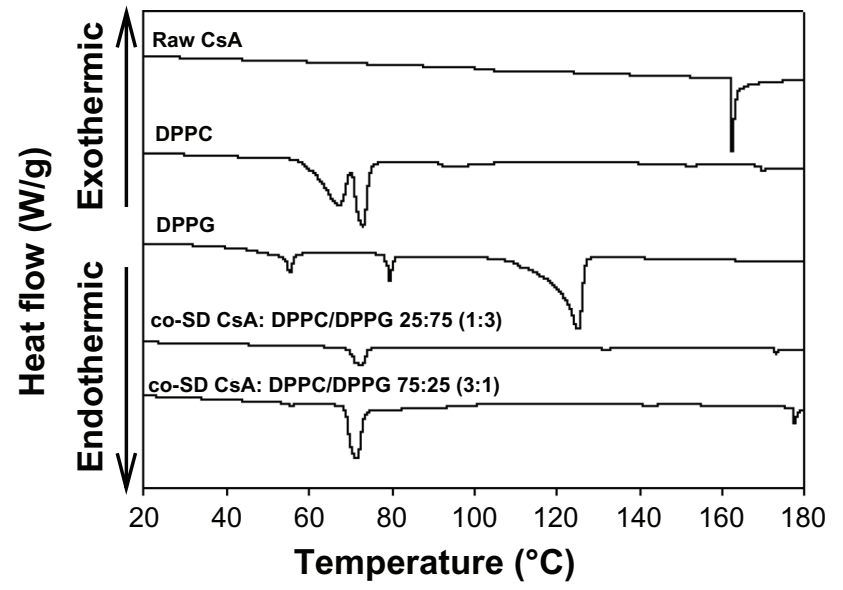

Figure 4 Representative differential scanning calorimetry thermograms at $5^{\circ} \mathrm{Cl}$ minute heating scan rate of raw CsA, pure DPPC, pure DPPG, and organic solution advanced co-SD lung surfactant-mimic powders of co-SD CsA:DPPC/DPPG 25:75 (I:3) and co-SD CsA:DPPC/DPPG 75:25 (3:I).

Abbreviations: CsA, cyclosporine A; DPPC, dipalmitoylphosphatidylcholine; DPPG, dipalmitoylphosphatidylglycerol; SD, spray dried. 
25:75 and co-SD CsA:DPPC/DPPG 75:25 compositions encapsulated in lung surfactant-mimic DPPC/DPPG (3:1) show a bilayer main phase transition temperature $\left(\mathrm{T}_{\mathrm{m}}\right)$ at $72.8^{\circ} \mathrm{C}$ and $71.1^{\circ} \mathrm{C}$, respectively, which are below the individual $\mathrm{T}_{\mathrm{m}}$ values of DPPC and DPPG described above. The co-SD aerosol powders did not exhibit a CsA melting peak complete miscibility with the phospholipids (ie, no drug-rich phase separation was detected).

\section{XRPD}

The molecular state of the raw CsA versus SD CsA aerosol powder formulations was further evaluated by XRPD to measure the degree of molecular order (ie, crystallinity) versus molecular disorder (ie, noncrystallinity), which is an important physicochemical property for dry powder aerosols. In Figure 5, the XRPD diffractogram of raw CsA shows sharp diffraction peaks in the range of 5-10 $2 \theta$ degrees and in the range of 14-20 $2 \theta$ degrees. This indicates a partially crystalline powder with defined structural molecular order in the solid state that is observed in liquid crystals and heteropolypeptides having secondary structure in the solid state such as $\alpha$-helical and/or $\beta$-sheet secondary structure conformations. ${ }^{30,51}$ In contrast, the XRPD diffractograms for the various SD CsA aerosol powders showed the absence of the sharp peaks and the distinctive diffuse "halo" that is characteristic of noncrystalline powders suggesting the amorphous state of the SD CsA powders. The broad peaks in the range of secondary structure conformations of CsA are still evident, suggesting the retention of secondary conformation following SD.

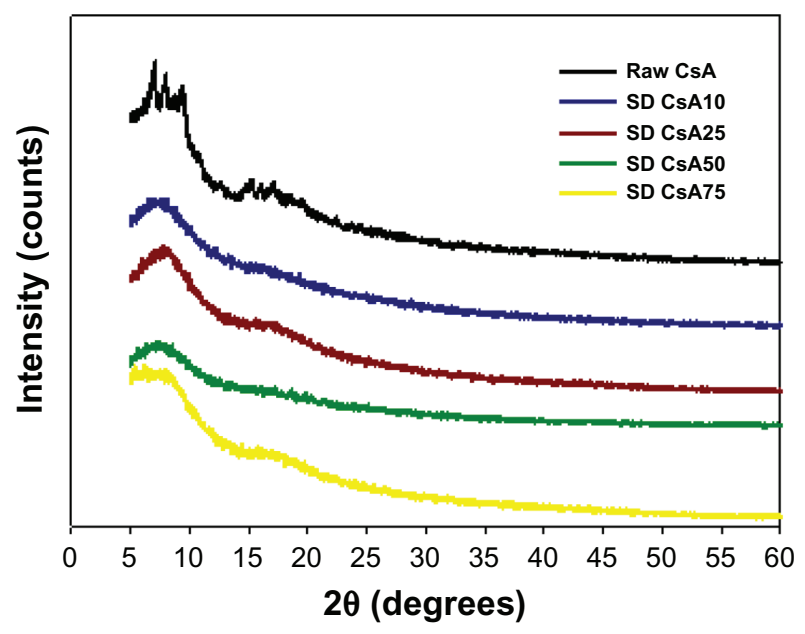

Figure 5 Representative X-ray powder diffractograms of raw CsA and various organic solution advanced SD CsA aerosol powders.

Notes: 10, 25, 50, and 75 indicate a pump rate of $10 \%, 25 \%, 50 \%$, and $75 \%$, respectively. Abbreviations: CsA, cyclosporine A; SD, spray dried.
Diffractograms of the co-SD respirable powders are shown in Figure 6. DPPC and DPPG show a distinct peak in the range of 20-25 $2 \theta$ degrees, which is the characteristic range indicative of the solid-state phospholipid bilayer structure. ${ }^{52}$ This characteristic peak is also clearly evident in the co-SD CsA:DPPC/DPPG respirable powders, which indicates preservation of the solid-state phospholipid bilayer structure in these co-SD aerosol powder formulations.

\section{Cross-polarizing light hot-stage microscopy}

Figure 7 shows the cross-polarized light optical microscope images for the phase transitions of raw $\mathrm{CsA}$ at a heating scan rate of $5^{\circ} \mathrm{C} /$ minute, which is the same rate as employed in thermal analysis by DSC. Minimal birefringency is detected, which agrees with the XRPD diffractogram. At $140.6^{\circ} \mathrm{C}$, raw CsA exhibited small crystals (Figure 7A). When temperature increased to $161.1^{\circ} \mathrm{C}, \mathrm{CsA}$ started to melt (Figure 7B). The onset temperature coincided with its melting as measured by DSC thermal analysis. Figure 7C shows the liquid state of CsA after melting.

Figure 8 shows representative cross-polarized light optical microscope images for the phase transitions of SD CsA aerosol powders. Various SD batches generated similar images to the representative images shown for the SD CsA aerosol powder at a $10 \%$ pump rate. As shown in Figure $8 \mathrm{~A}$, $\mathrm{SD}$ CsA at a $10 \%$ pump rate at $25^{\circ} \mathrm{C}$ exhibited the complete absence of birefringency, which is characteristic of noncrystalline powders. At $152^{\circ} \mathrm{C}$, the aerosol powder started to melt (Figure $8 \mathrm{C}$ ), which was in a good agreement with the DSC thermal analysis data of SD CsA at a $10 \%$ pump rate

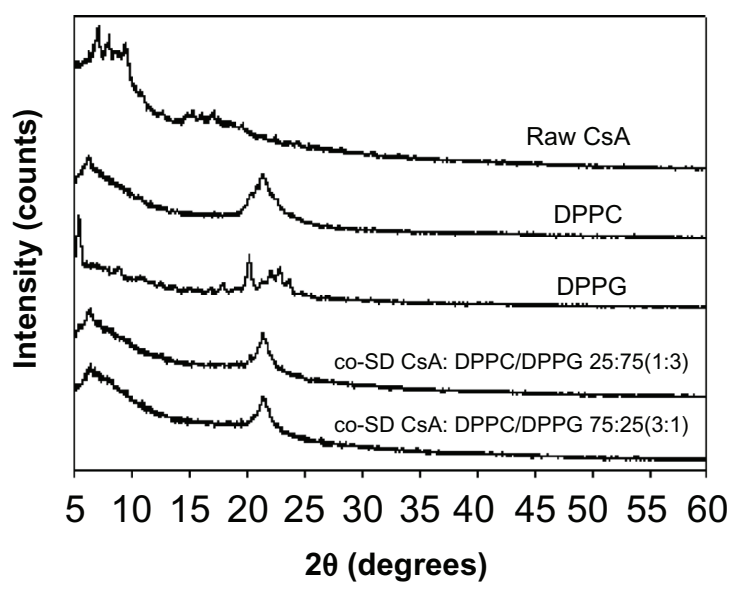

Figure 6 Representative X-ray powder diffractograms of raw CsA, pure DPPC, pure DPPG, and organic solution advanced co-SD CsA lung surfactant-mimic powders of co-SD CsA:DPPC/DPPG 25:75 (I:3) and co-SD CsA:DPPC/DPPG 75:25 (3:1).

Abbreviations: CsA, cyclosporine A; DPPC, dipalmitoylphosphatidylcholine; DPPG, dipalmitoylphosphatidylglycerol; SD, spray dried. 

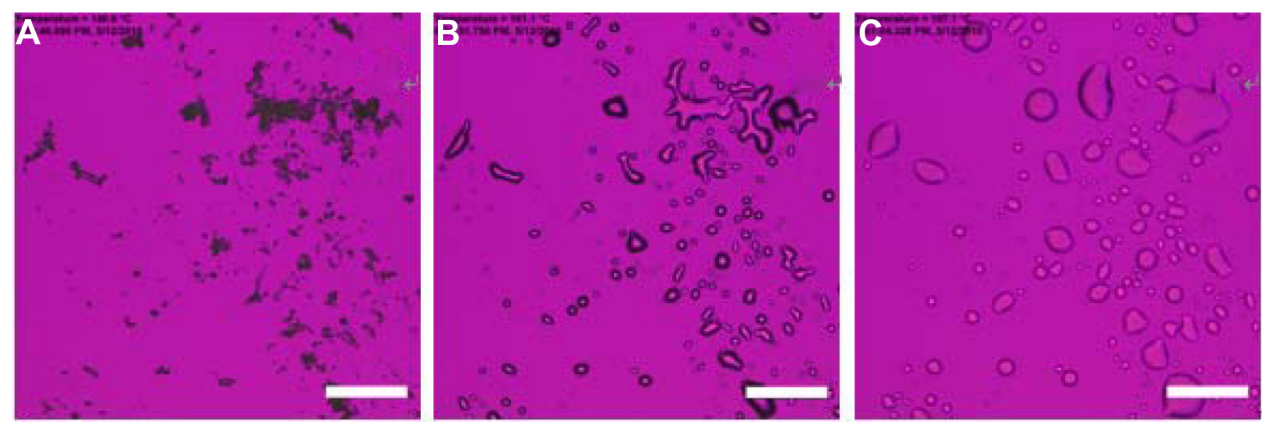

Figure 7 Representative cross-polarized light optical microscope images of the phase transitions for raw cyclosporine $\mathrm{A}$ heated from $25^{\circ} \mathrm{C}$ to $200^{\circ} \mathrm{C}$ at $5^{\circ} \mathrm{C} / \mathrm{minute}$ The temperature for each graph is $(\mathbf{A}) 140.6^{\circ} \mathrm{C}$; (B) $161.1^{\circ} \mathrm{C}$; and (C) $197.1^{\circ} \mathrm{C}$.

Note: Scale bar represents $0.2 \mathrm{~mm}$.

(Figure 4). At $188^{\circ} \mathrm{C}, \mathrm{SD}$ CsA at a $10 \%$ pump rate existed completely as a liquid (Figure 8D).

\section{CD spectroscopy}

Figure 9 shows the $\mathrm{CD}$ spectrum of $\mathrm{CsA}$ at $25^{\circ} \mathrm{C}$ in methanol. The distinct pattern observed in the CD spectrum clearly indicates the presence of secondary structure, suggesting the presence of an $\alpha$-helix conformation. This makes sense given the polypeptide structure of CsA.

\section{Karl Fischer coulometric titration}

The residual water content values for all one-component CsA powders were quantified analytically by Karl Fischer coulometric titration and are shown in Table 4. The residual water content before SD for raw CsA was $1.64 \%$, which is low as would be expected due to the hydrophobic nature of CsA. After advanced organic solution SD from the alcohol methanol, the value was further reduced to remarkably low levels that are well within recommended levels for DPIs. Moreover, the extent of remarkable reduction in the residual water percentage in the aerosol powders depended on the pump rate. At the lowest SD pump rate used in these experiments of $10 \%$ (ie, slowest SD process), SD CsA had the lowest water content $(0.7 \%)$, and water content was increased with each increment in the percentage of pump rate used in the SD process. When a higher pump rate of $75 \%$ was used (ie, faster SD process), the SD sample had a residual water content of $1.60 \%$, which is still low and similar to that measured in raw CsA. These results are in good agreement with the data from the gravimetric vapor sorption analysis (Figure 10).

Low residual water content also existed in the multifunctional co-SD CsA lung surfactant-mimic aerosol formulations. Before SD, the mean values of water content of raw CsA, DPPC, and DPPG were $1.64 \%, 1.95 \%$, and $0.51 \%$, respectively (Table 5). After organic solution advanced SD, the residual water content of co-SD CsA:DPPC/DPPG lung surfactant-mimic aerosol powder formulation was reduced further to $\sim 1.1 \%$ (lower than that of raw CsA and raw DPPC), which is favorable for superior DPI aerosolization and is well within the recommended levels for dry powders. Low water content in aerosol powders is important for pharmaceutical stability and improved aerosol dispersion performance. . $3,24,26,40,42^{2}$

\section{Gravimetric water vapor sorption}

Figure 10 shows the water vapor absorption isotherms for raw CsA and SD CsA aerosol powders produced at various SD pump rates. These profiles show that the hydrophobic nature of CsA appears to dominate its low water vapor uptake
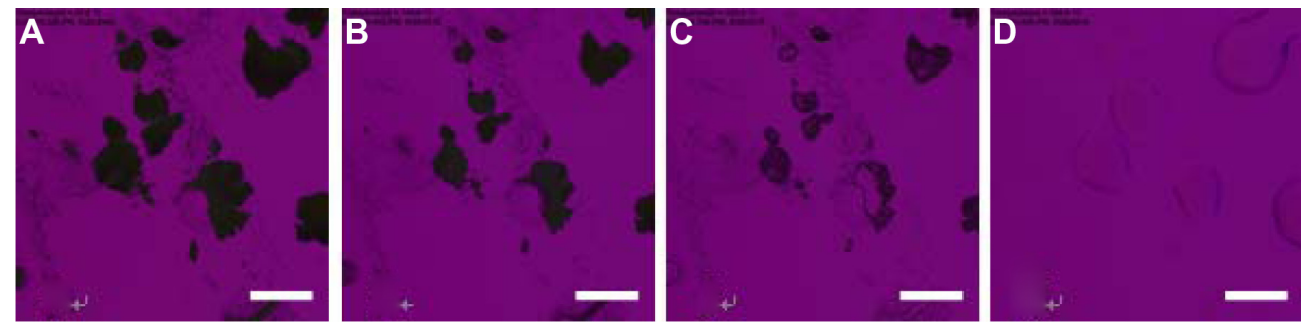

Figure 8 Representative cross-polarized light optical microscope images for the phase transitions of spray-dried cyclosporine A at a $10 \%$ pump rate. The samples were heated from $25^{\circ} \mathrm{C}$ to $200^{\circ} \mathrm{C}$ at $5^{\circ} \mathrm{C} /$ minute. The temperature for each graph is (A) $25^{\circ} \mathrm{C}$; (B) $146.8^{\circ} \mathrm{C}$; (C) $152^{\circ} \mathrm{C}$; and (D) $188^{\circ} \mathrm{C}$. Note: Scale bar represents $0.2 \mathrm{~mm}$. 


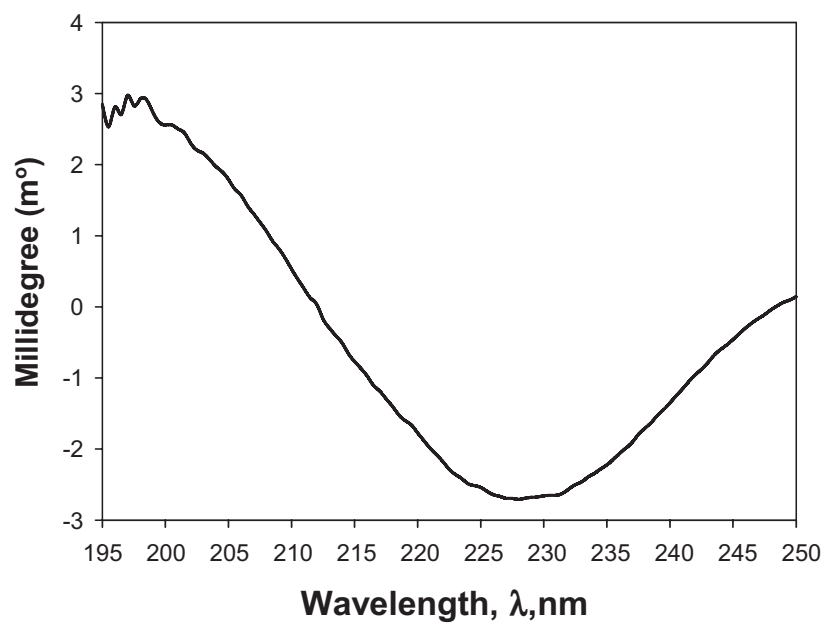

Figure 9 Representative circular dichroism $\left(\mathrm{m}^{\circ}\right)$ spectrum of cyclosporine $A$ at $25^{\circ} \mathrm{C}$ in methanol.

in the solid state for the raw and SD CsA aerosol powders. These isotherms are in good agreement with Karl Fisher values, which also revealed low residual water content in all powders under ambient RH conditions. This is favorable for enhanced aerosol dispersion performance as DPIs. ${ }^{23,24,26,40,42}$ Indeed, these are high performing aerosols as DPIs (to be discussed).

The maximal absorption weight change percentage values for SD CsA aerosol powders at high lung RH levels modeled at $90 \%$ and $93 \% \mathrm{RH}$ are shown in Table 5. This is the maximal water percentage absorbed by the respirable powders at these very high RH levels, which is low and as expected for hydrophobic powders.

For co-SD CsA:DPPC/DPPG 25:75 and co-SD CsA:DPPC/DPPG 75:25, the rate of water vapor absorption isotherms remained relatively similar to one another at all RH levels (Figure 11). The maximal absorption weight change percentage values at high lung $\mathrm{RH}$ levels modeled at 90\% and 93\% RH are stated in Table 6. The maximal water percentage absorbed at $90 \% \mathrm{RH}$ and $93 \% \mathrm{RH}$ reveals that

Table 4 Water content (weight change percentage) by Karl Fisher titration for raw cyclosporine $A$ and spray-dried cyclosporine $A$ powders at various spray drying pump rates

\begin{tabular}{ll}
\hline Sample & Water content, \% \\
\hline Raw CsA & $1.64 \pm 0.08$ \\
SD CsA 10\%P & $0.70 \pm 0.33$ \\
SD CsA 25\%P & $1.00 \pm 0.08$ \\
SD CsA 50\%P & $1.33 \pm 0.16$ \\
SD CsA 75\%P & $1.60 \pm 0.24$ \\
\hline
\end{tabular}

Notes: Mean \pm standard deviation, $n=3$.

Abbreviations: \%P, pump rate; CsA, cyclosporine A; SD, spray dried.
DPPC dominates the maximal values for the co-SD CsA lung surfactant-mimic aerosol powders. This property may aid in improving wettability, spreading, and absorption in the lungs. DPPC bilayers undergo a lyotropic phase transition in the solid state from the gel to the liquid crystal at RH values greater than $75 \%$, as reported earlier. ${ }^{46}$ Sodium DPPG absorbed much less water due to its tightly packed bilayer as a result of favorable electrostatic interactions between the cationic sodium ion and anionic polar headgroup, which is in good agreement with an earlier report. ${ }^{46}$ At intermediate $\mathrm{RH}$ regions, the weight change percentage of DPPG showed a plateau with an increasing $\mathrm{RH}$ between $20 \%-70 \%$ but increased significantly when the RH exceeded $\sim 70 \%$. The plateau region is indicative of a crystal-to-gel bilayer lyotropic phase transition, as reported earlier. ${ }^{46}$

\section{In vitro aerosol dispersion performance by the NGI}

Figure 12 shows the DPI aerosol dispersion and deposition profile for novel SD CsA DPI aerosols and multifunctional co-SD CsA:DPPC/DPPG lung surfactant-mimic DPI aerosols aerosolized using a United States (US) Food and Drug Administration (FDA)-approved DPI device, the HandiHaler. As seen in Figure 12, measurable deposition is present on all stages including the lowest stages of stages six and seven. Outstanding deposition on stages modeled for middle lung and deep lung delivery is present for all DPI aerosols. Distinct trends are seen in SD pump rate effect on tailoring the aerosol deposition patterns for SD CsA aerosols. Namely, the SD CsA powders produced at the lower SD pump rates of $50 \%$ and $25 \%$ appear to give increased aerosol deposition on the lower NGI stages, which are modeled to predict deeper lung delivery. Specifically, at a $75 \%$ pump rate, the aerosol deposition peak mode is on stage three, while the aerosol deposition peak mode is on stage four for aerosols engineered at a $50 \%$ pump rate and $25 \%$ pump rate. The aerosol peak mode for all co-SD CsA:DPPC/DPPG lung surfactant-mimic DPI aerosols is on stage four, with higher deposition than SD CsA aerosols on stage four.

Table 7 shows the aerosol performance parameters for the novel SD CsA DPI aerosol powders and the co-SD CsA lung surfactant-mimic DPI aerosol powders. The ED values are very high in the range of $\sim 80 \%-85 \%$ and represent efficiency in aerosolization for SD CsA aerosols. The ED values for co-SD CsA lung surfactant-mimic DPI aerosol powders are even higher, suggesting that the presence of DPPC/ DPPG lung surfactant favorably enhances the aerosolization 

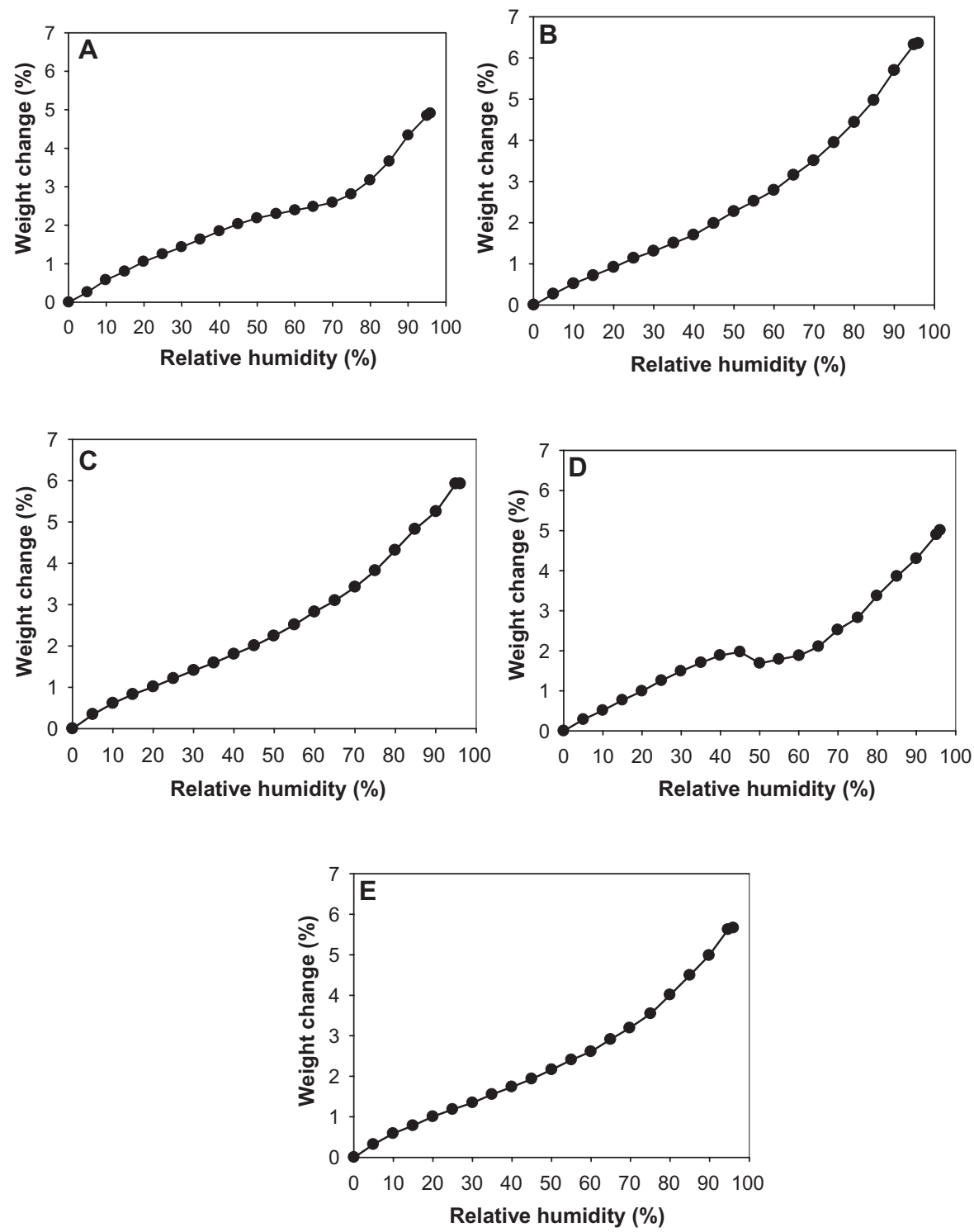

Figure 10 Gravimetric water vapor absorption isotherms for (A) raw cyclosporine $A$ and spray-dried cyclosporine at a (B) $10 \%$ pump rate; (C) $25 \%$ pump rate; (D) $50 \%$ pump rate; and (E) $75 \%$ pump rate.

Table 5 Residual water content (weight change percentage) of raw cyclosporine A, lung surfactant-mimic phospholipids (dipalmitoylphosphatidylcholine and dipalmitoylphosphatidylglycerol), and cospray-dried cyclosporine A: dipalmitoylphosphatidylcholine/ dipalmitoylphosphatidylglycerol inhalation powders before and after organic solution advanced cospray drying

\begin{tabular}{ll}
\hline Sample & Water content, \% \\
\hline Raw CsA & $1.64 \pm 0.10$ \\
DPPC & $1.95 \pm 0.45$ \\
DPPG & $0.51 \pm 0.77$ \\
co-SD CsA:DPPC/DPPG 25:75 (I:3) & $1.16 \pm 0.37$ \\
co-SD CsA:DPPC/DPPG 75:25 (3:1) & $1.12 \pm 0.52$ \\
\hline
\end{tabular}

Notes: Mean \pm standard deviation, $n=5$.

Abbreviations: CsA, cyclosporine A; DPPC, dipalmitoylphosphatidylcholine; DPPG, dipalmitoylphosphatidylglycerol; SD, spray dried. efficiency process. This makes sense as these phospholipids are inherently surface active and can reduce interparticulate interactions, which will enhance dispersion of DPI aerosols. The values of RF are very high in the range of $~ 90 \%-95 \%$ for SD CsA aerosols and similarly very high for the co-SD CsA:DPPC/DPPG lung surfactant-mimic dry powder aerosols. The values of FPF are also remarkably high at $~ 50 \%$ for SD CsA aerosols. These high FPF values are significantly greater than the $\sim 10 \%-20 \%$ that is often observed for commercially marketed pharmaceutical inhalation aerosol products. ${ }^{53,54}$ The MMAD values are in the optimal size range of 2.5-3 $\mu \mathrm{m}$ for all aerosol powders, which is optimal for high lung deposition targeting the smaller airways. 


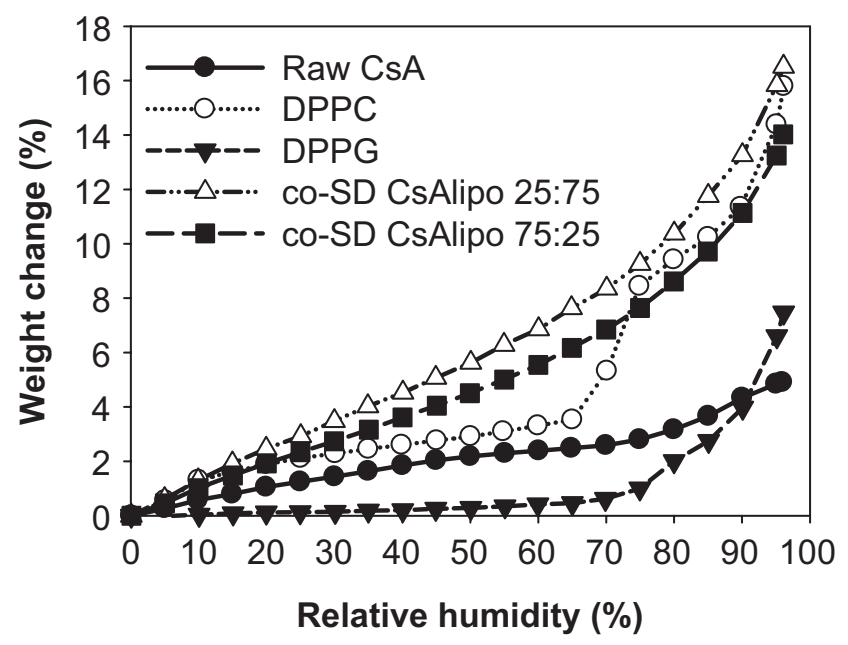

Figure I I Gravimetric water vapor absorption isotherms for raw CsA, pure DPPC, pure DPPG, and organic solution advanced co-SD CsA:DPPC/DPPG dry powder formulations of "CsA lipo 25:75" for co-SD CsA:DPPC/DPPG 25:75 (I:3) and "CsA lipo 75:25" for co-SD CsA:DPPC/DPPG 75:25 (3:1).

Abbreviations: CsA, cyclosporine A; DPPC, dipalmitoylphosphatidylcholine; DPPG, dipalmitoylphosphatidylglycerol; lipo, lipospheres; SD, spray dried.

\section{Discussion}

In this systematic and comprehensive study, novel SD CsA DPIs and multifunctional co-SD CsA:DPPC/DPPG lung surfactant-mimic DPIs were rationally designed and successfully produced. Respiratory delivery of CsA incorporated in biocompatible biodegradable DPPC/DPPG in the solid state as DPI aerosols would facilitate CsA delivery with high local concentration in the smaller airways of the lung. Additionally, these high-performing DPI aerosols are multifunctional and have nanomedicine properties associated with the lung surfactant-mimic phospholipids - DPPC/DPPG - for targeted pulmonary nanomedicine. In addition, improved absorption

Table $\mathbf{6}$ The maximal weight change percentages by water absorption at $90 \%$ and $93 \%$ relative humidity for raw versus cospray-dried cyclosporine A: dipalmitoylphosphatidylcholine/ dipalmitoylphosphatidylglycerol particles for dry powder inhalation aerosol powder formulations

\begin{tabular}{lll}
\hline Sample & wt\% at $\mathbf{9 0 \%} \mathbf{R H}$ & wt\% at $\mathbf{9 3} \% \mathbf{R H}$ \\
\hline Raw CsA & 4.33 & 4.56 \\
DPPC & 11.40 & 13.19 \\
DPPG & 3.98 & 5.47 \\
co-SD CsA:DPPC/ & 13.26 & 14.83 \\
DPPG 25:75 (1:3) & & \\
co-SD CsA:DPPC/ & 11.14 & 12.24 \\
DPPG 75:25 (3:1) & &
\end{tabular}

Abbreviations: CsA, cyclosporine A; DPPC, dipalmitoylphosphatidylcholine; DPPG, dipalmitoylphosphatidylglycerol; RH, relative humidity; SD, spray dried; wt\%, weight change percentage. due to improved wettability may be offered by the presence of these phospholipids. Novel organic solution advanced SD particles and co-SD lung surfactant-mimic particles all were successfully designed under a rationally chosen advanced SD closed mode condition with the primary particle size below $5.0 \mu \mathrm{m}$ and aerosol deposition on the lower stages of the NGI all the way to the lowest NGI stage seven.

All aerosol powder formulations were unimodal with a narrow size distribution. All SD CsA powders appeared to be amorphous based on the XRPD data. The SD CsA powders produced at the lower SD pump rates of $50 \%$ and $25 \%$ appeared to provide increased aerosol deposition on the lower NGI stages, which are modeled to predict deeper lung delivery. Specifically, at a $75 \%$ pump rate, the aerosol deposition peak mode is on stage three, while the aerosol deposition peak mode is on stage four for aerosols engineered at a $50 \%$ and $25 \%$ pump rate. The aerosol peak mode for all co-SD CsA:DPPC/DPPG lung surfactant-mimic DPI aerosols is on NGI stage four, with higher deposition than SD CsA aerosols on NGI stage four.

SD is a commonly used method in the preparation of inhalation powders..$^{55,56}$ To tailor and optimize the particle characteristics, the SD operating parameters can be modified and include solvent type (organic or aqueous), solute concentration, atomization pressure, feed properties, pump rate, gas type, airflow, and drying temperature. ${ }^{22,27,57}$ In this study, pure alcohol solutions were used in organic solution $\mathrm{SD}$ and co-SD in closed mode to effectively reduce both the residual water content and particle size due to its nonaqueous nature and lower surface tension. In addition, the specific method reported here enables high-throughput optimization. Compared to water's high surface tension $(72 \mathrm{mN} / \mathrm{m})$, alcohols such as methanol (which are also regarded as "green chemicals") have a much lower surface tension in the range of $22-25 \mathrm{mN} / \mathrm{m}$. It is observed that rationally choosing the SD pump rate enabled tailoring of the respirable article size and particle surface morphology, which provided excellent dispersion as dry powder aerosols and resulted in high aerosol performance values for all SD and co-SD aerosol formulations in this study.

Preservation of the phospholipid bilayer structure in the solid state following organic solution SD in closed mode was successfully achieved for all co-SD CsA:DPPC/DPPG powders, as confirmed by XRPD and DSC. The small particle size, unimodal narrow size distribution, particle morphology, surface morphology, and very low residual water content of all co-SD aerosol formulations were all suitable for targeted 


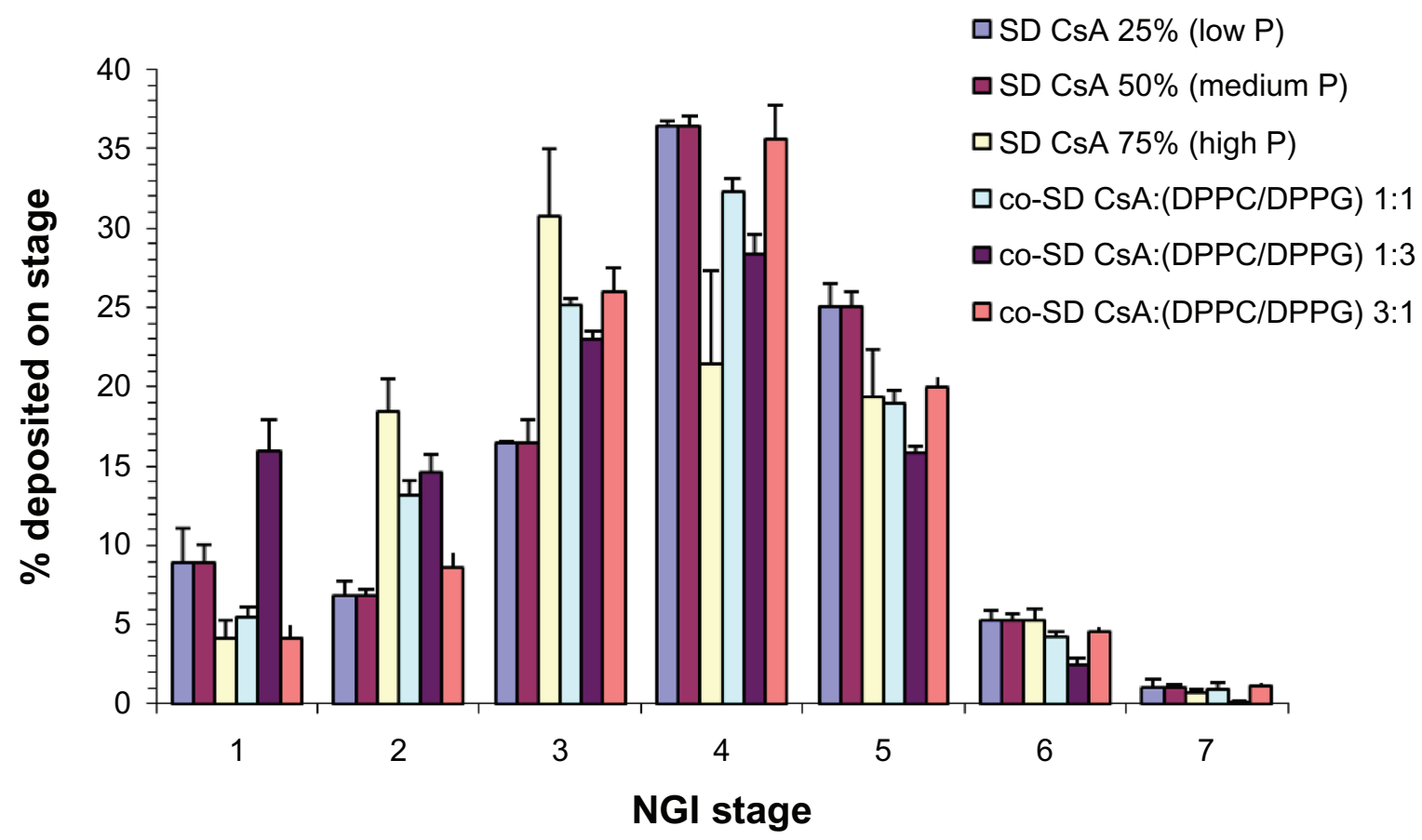

Figure 12 Therapeutic aerosol dispersion performance of dry powder inhalers as percentage deposition on each stage of the NGI at an airflow rate ( $Q$ ) of $60 \mathrm{~L} /$ minute for SD CsA and co-SD CsA:DPPC/DPPG DPI aerosol systems. For the NGI at $\mathrm{Q}=60 \mathrm{~L} /$ minute, the NGl stage cutoff diameters are as follows: stage one (8.06 $\mu \mathrm{m})$, stage two $(4.46 \mu \mathrm{m})$, stage three $(2.82 \mu \mathrm{m})$, stage four $(1.66 \mu \mathrm{m})$, stage five $(0.94 \mu \mathrm{m})$, stage six $(0.55 \mu \mathrm{m})$, and stage seven $(0.34 \mu \mathrm{m})$.

Abbreviations: CsA, cyclosporine A; DPPC, dipalmitoylphosphatidylcholine; DPPG, dipalmitoylphosphatidylglycerol; NGI, next generation impactor; P, pump rate; $\mathrm{SD}$, spray dried.

respiratory drug delivery. Organic solution advanced SD in closed mode enabled all aerosol powders to have remarkably low residual water content which enhanced aerosol dispersion performance, as reflected in remarkably high ED percentage, RF percentage, and FPF percentage aerosol parameter values. The MMAD values were in the optimal range of 2.5-3 $\mu \mathrm{m}$ for targeting the smaller airways.

Excellent aerosol dispersion performance was demonstrated using the NGI coupled with the HandiHaler DPI device, which clearly indicated that the formulated particles would be optimal for targeted delivery as aerosolized powders. This demonstrates for the first time the significant potential of these various advanced DPI aerosols (designed and optimized by organic solution advanced SD in closed mode) to be utilized to effectively deliver SD CsA alone and with lung surfactant-mimic phospholipids - DPPC/ DPPG - for targeted lung transplant immunosuppression with multifunctional properties as DPI aerosols.

Table 7 Aerosol dispersion performance properties of aerosolized dry powders including emitted dose, fine particlefraction, respirable fraction, mass median aerodynamic diameter, and geometric standard deviation for inhalable microparticle/nanoparticle formulations of spray-dried cyclosporine A and cospray-dried cyclosporine A: dipalmitoylphosphatidylcholine/dipalmitoylphosphatidylglycerol dry powder inhalation aerosol systems

\begin{tabular}{|c|c|c|c|c|c|}
\hline \multirow{2}{*}{$\begin{array}{l}\text { Dry powder inhalation aerosol system } \\
\text { SD and co-SD powders }\end{array}$} & \multicolumn{5}{|c|}{ Aerosol performance parameters } \\
\hline & ED, \% & FPF, \% & $\mathbf{R F}, \%$ & MMAD, $\mu \mathrm{m}$ & GSD \\
\hline SD CsA 25\%P & $81.10 \pm 9.29$ & $49.52 \pm 3.25$ & $91.35 \pm 8.59$ & $2.18 \pm 0.09$ & $1.77 \pm 0.03$ \\
\hline SD CsA $50 \% \mathrm{P}$ & $79.00 \pm 4.39$ & $51.22 \pm 3.15$ & $96.14 \pm 1.30$ & $2.26 \pm 0.06$ & $1.71 \pm 0.02$ \\
\hline SD CsA 75\%P & $85.21 \pm 5.57$ & $52.14 \pm 12.48$ & $95.82 \pm 1.36$ & $2.75 \pm 0.47$ & $1.79 \pm 0.19$ \\
\hline co-SD CsA:DPPC/DPPG 25:75 (I:3) & $89.06 \pm 1.69$ & $39.09 \pm 1.40$ & $84.08 \pm 0.74$ & $3.01 \pm 0.05$ & $2.16 \pm 0.06$ \\
\hline co-SD CsA:DPPC/DPPG 50:50 (I:I) & $83.12 \pm 1.46$ & $48.42 \pm 3.83$ & $94.55 \pm 1.00$ & $2.57 \pm 0.04$ & $1.86 \pm 0.04$ \\
\hline co-SD CsA:DPPC/DPPG 75:25 (3:I) & $85.40 \pm 1.04$ & $52.99 \pm 4.12$ & $96.15 \pm 8.65$ & $2.79 \pm 0.47$ & $1.85 \pm 0.05$ \\
\hline
\end{tabular}

Notes: Mean \pm standard deviation, $\mathrm{n}=3$.

Abbreviations: \%P, pump rate; CsA, cyclosporine A; DPPC, dipalmitoylphosphatidylcholine; DPPG, dipalmitoylphosphatidylglycerol; ED, emitted dose; FPF, fine particle fraction; GSD, geometric standard deviation; MMAD, mass median aerodynamic diameter; RF, respirable fraction; SD, spray dried. 


\section{Conclusion}

Novel DPI aerosol formulations of CsA for pulmonary delivery were rationally designed and successfully developed by the novel particle engineering design process technology of organic solution advanced SD from alcohol solutions at several rationally chosen pump rates. All DPI SD CsA aerosol powders had excellent physicochemical properties with optimal particle morphology, surface morphology, and very low residual water content. The aerosol dispersion parameters of ED, FPF, and RF were all high. The MMAD values were low and in the optimal range for targeting the smaller airways.

In addition, co-SD multifunctional dry powder aerosols consisting of co-SD CsA:DPPC/DPPG showed excellent physicochemical and aerosol dispersion properties as highperforming DPIs with very low residual water content. The phospholipid bilayer structure was preserved in the solid state, as confirmed by DSC and XRPD analyses. As reported here, the DPI aerosol delivery systems of SD CsA and co-SD CsA:DPPC/DPPG have the potential to significantly reduce the side effects associated with the systemic exposure of CsA, leading to a wider therapeutic safety margin and enhanced patient outcomes/quality of life in lung transplant patients.

\section{Acknowledgments}

Dr Dicky Yu (University of Kentucky College of Agriculture) is thanked for SEM access. Dr Tonglei Li (University of Kentucky College of Pharmacy) is thanked for XRPD and hot-stage microscopy access. DrTrevor Creamer (Department of Chemistry, University of Kentucky) is thanked for CD access.

\section{Disclosure}

The authors report no conflicts of interest in this work.

\section{References}

1. Waldrep JC, Scherer PW, Keyhani K, and Knight V. Cyclosporin A liposome aerosol: particle size and calculated respiratory deposition. Int J Pharm. 97:205-212 (1993).

2. Matsuda S, Koyasu S. Mechanisms of action of cyclosporine. Immunopharmacology. 2000;47(2-3):119-125.

3. Underwood SL, McMillan S, Reeves R, etal. Effects of cyclosporin A administered into the airways against antigen-induced airway inflammation and hyperreactivity in the rat. Eur J Pharmacol. 2001;420(2-3): 165-173.

4. Mitruka SN, Won A, McCurry KR, et al. In the lung aerosol cyclosporine provides a regional concentration advantage over intramuscular cyclosporine. J Heart Lung Transplant. 2000;19(10):969-975.

5. Shirbacheh MV, Jones JW, Breidenbach WC, McCabe S, Barker JH, Gruber SA. The case for local immunosuppression in composite tissue allotransplantation. Transplant Proc. 1998;30(6):2739-2742.

6. Kahan BD. Cyclosporine. New Engl J Med. 1989;321(25): 1725-1738.
7. Burkart GJ, Smaldone GC, Eldon MA, et al. Lung deposition and pharmacokinetics of cyclosporine after aerosolization in lung transplant patients. Pharm Res. 2003;20(2):252-256.

8. Rohatagi S, Calic F, Harding N, et al. Pharmacokinetics, pharmacodynamics, and safety of inhaled cyclosporin A (ADI628) after single and repeated administration in healthy male and female subjects and asthmatic patients. J Clin Pharmacol. 2000;40(11):1211-1226.

9. Niven RW. Toward managing chronic rejection after lung transplant: the fate and effects of inhaled cyclosporine in a complex environment. Adv Drug Deliv Rev. 2011;63(1-2):88-109.

10. Corcoran TE, Smaldone GC, Dauber JH, et al. Preservation of posttransplant lung function with aerosol cyclosporin. Eur Respir J. 2004; 23(3):378-383.

11. Iacono AT, Corcoran TE, Griffith BP, et al. Aerosol cyclosporin therapy in lung transplant recipients with bronchiolitis obliterans. Eur Respir J. 2004;23(3):384-390.

12. Hayes D Jr, Zwischenberger JB, Mansour HM. Aerosolized tacrolimus: a case report in a lung transplant recipient. Transplant Proc. 2010; 42(9):3876-3879.

13. Behr J, Zimmermann G, Baumgartner R, et al. Lung deposition of a liposomal cyclosporine A inhalation solution in patients after lung transplantation. J Aerosol Med Pulm Drug Deliv. 2009;22(2):121-130.

14. Onoue S, Sato H, Kawabata Y, Mizumoto T, Hashimoto N, Yamada S. In vitro and in vivo characterization on amorphous solid dispersion of cyclosporine A for inhalation therapy. J Control Release. 2009; 138(1):16-23.

15. Zijlstra GS, Rijkeboer M, Jan van Drooge D, et al. Characterization of a cyclosporine solid dispersion for inhalation. AAPS J. 2007;9(2):E190-E199.

16. Yamasaki K, Kwok PC, Fukushige K, Prud'homme RK, Chan HK. Enhanced dissolution of inhalable cyclosporine nano-matrix particles with mannitol as matrix former. Int J Pharm. 2011;420(1):34-42.

17. Chen X, Young TJ, Sarkari M, Williams RO 3rd, Johnston KP. Preparation of cyclosporine A nanoparticles by evaporative precipitation into aqueous solution. Int J Pharm. 2002;242(1-2):3-14.

18. Park CW, Hayes D Jr, Mansour HM. Pulmonary inhalation aerosols for targeted antibiotics drug delivery. Eur Pharm Rev. 2011;16(1): $32-36$.

19. Hickey AJ, Mansour HM. Delivery of drugs by the pulmonary route. In: Florence AT, Siepmann J, editors. Modern Pharmaceutics: Volume 2. 5th ed. New York, NY: Informa Healthcare; 2009:191-220.

20. Patton JS, Byron PR. Inhaling medicines:delivering drugs to the body through the lungs. Nat Rev Drug Discov. 2007;6(1):67-74.

21. Hayes D Jr, Mansour HM, Kirkby S, Phillips AB. Rapid acute onset of bronchiolitis obliterans syndrome in a lung transplant recipient after respiratory syncytial virus infection. Transpl Infect Dis. 2012; 14(5):548-550.

22. Hickey AJ, Mansour HM. Formulation challenges of powders for the delivery of small molecular weight molecules as aerosols. In: Rathbone MJ, Hadgraft J, Roberts MS, Lane ME, editors. ModifiedRelease Drug Delivery Technology: Volume 2. 2nd ed. New York, NY: Informa Healthcare; 2008:573-602.

23. Hickey AJ, Mansour HM, Telko MJ, et al. Physical characterization of component particles included in dry powder inhalers. I. Strategy review and static characteristics. J Pharm Sci. 2007;96(5):1282-1301.

24. Hickey AJ, Mansour HM, Telko MJ, et al. Physical characterization of component particles included in dry powder inhalers. II. Dynamic characteristics. J Pharm Sci. 2007;96(5):1302-1319.

25. Willis L, Hayes D Jr, Mansour HM. Therapeutic liposomal dry powder inhalation aerosols for targeted lung delivery. Lung. 2012;190(3): 251-262.

26. Wu X, Li X, Mansour HM. Surface analytical techniques in solid-state particle characterization for predicting performance in dry powder inhalers. KONA Powder Part J. 2010;28:3-19.

27. Mansour HM, Rhee YS, Wu X. Nanomedicine in pulmonary delivery. Int J Nanomedicine. 2009;4:299-319. 
28. Mansour H, Wang DS, Chen CS, Zografi G. Comparison of bilayer and monolayer properties of phospholipid systems containing dipalmitoylphosphatidylglycerol and dipalmitoylphosphatidylinositol. Langmuir. 2001;17(21):6622-6632.

29. Mansour HM, Zografi G. Relationships between equilibrium spreading pressure and phase equilibria of phospholipid bilayers and monolayers at the air-water interface. Langmuir. 2007;23(7):3809-3819.

30. Mansour HM, Damodaran S, Zografi G. Characterization of the in situ structural and interfacial properties of the cationic hydrophobic heteropolypeptide, KL4, in lung surfactant bilayer and monolayer models at the air-water interface: implications for pulmonary surfactant delivery. Mol Pharm. 2008;5(5):681-695.

31. Morrow MR, Temple S, Stewart J, Keough KM. Comparison of DPPC and DPPG environments in pulmonary surfactant models. Biophys $J$ 2007;93(1):164-175.

32. Goerke J. Pulmonary surfactant: functions and molecular composition. Biochim Biophys Acta. 1998;1408(2-3):79-89.

33. Veldhuizen R, Nag K, Orgeig S, Possmayer F. The role of lipids in pulmonary surfactant. Biochim Biophys Acta. 1998;1408(2-3):90-108.

34. Postle AD, Heeley EL, Wilton DC. A comparison of the molecular species compositions of mammalian lung surfactant phospholipids. Comp Biochem Physiol A Mol Integr Physiol. 2001;129(1):65-73.

35. Mansour HM, Rhee YS, Park CW, DeLuca PP. Lipid nanoparticulate drug delivery and nanomedicine. In: Moghis A, editor. Lipids in Nanotechnology, 1st ed. Urbana, IL: AOCS Press; 2011:221-268.

36. Mansour HM, Park CW, Hayes D Jr. Nanoparticle lung delivery and inhalation aerosols for targeted pulmonary nanomedicine. In: Kumar A, Mansour HM, Friedman A, Blough E, editors. Nanomedicine in Drug Delivery: First edition. London: CRC Press/Taylor \& Francis; 2013 In press.

37. Rhee YS, Mansour HM. Nanopharmaceuticals I: nanocarrier systems in drug delivery. Int J Nanotechnol. 2011;8(1/2):84-114.

38. Wu X, Mansour HM. Nanopharmaceuticals II: application of nanoparticles and nanocarrier systems in pharmaceutics and nanomedicine. Int J Nanotechnol. 2011;8(1/2):115-145.

39. Ganguly S, Moolchandani V, Roche JA, et al. Phospholipid-induced in vivo particle migration to enhance pulmonary deposition. J Aerosol Med Pulm Drug Deliv. 2008;21(4):343-350.

40. Meenach SA, Vogt FG, Anderson KW, Hilt JZ, McGarry RC, Mansour HM. Design, physicochemical characterization, and optimization of organic solution advanced spray-dried inhalable dipalmitoylphosphatidylcholine (DPPC) and dipalmitoylphosphatidylethanolamine poly(ethylene glycol) (DPPE-PEG) microparticles and nanoparticles for targeted respiratory nanomedicine delivery as dry powder inhalation aerosols. Int J Nanomedicine. 2013;8:275-293.

41. Wu X, Hayes D Jr, Zwischenberger JB, Kuhn RJ, Mansour HM. Design and physicochemical characterization of advanced spray-dried tacrolimus multifunctional particles for inhalation. Drug Des Dev Ther. 2013;7:59-72.

42. Li X, Mansour HM. Physicochemical characterization and water vapor sorption of organic solution advanced spray-dried trehalose microparticles and nanoparticles for targeted dry powder pulmonary inhalation delivery. AAPS Pharm Sci Tech. 2011;12(4):1420-1430.
43. Xu Z, Mansour HM, Mulder T, McLean R, Langridge J, Hickey AJ. Dry powder aerosols generated by standardized entrainment tubes from drug blends with lactose monohydrate: 2 . Ipratropium bromide monohydrate and fluticasone propionate. J Pharm Sci. 2010;99(8):3415-3429.

44. Xu Z, Mansour HM, Mulder T, McLean R, Langridge J, Hickey AJ. Dry powder aerosols generated by standardized entrainment tubes from drug blends with lactose monohydrate: 1 . albuterol sulfate and disodium cromoglycate. J Pharm Sci. 2010;99(8):3398-3414.

45. Mansour HM, Xu Z, Hickey AJ. Dry powder aerosols generated by standardized entrainment tubes from alternative sugar blends: 3 . Trehalose dihydrate and D-mannitol carriers. J Pharm Sci. 2010;99(8): 3430-3441.

46. Mansour HM, Zografi G. The relationship between water vapor absorption and desorption by phospholipids and bilayer phase transitions. J Pharm Sci. 2007;96(2):377-396.

47. Aerosols, nasal sprays, metered-dose inhalers, and dry powder inhalers monograph. In: USP 29-NF 24: The United States Pharmacopeia and The National Formulary: The Official Compendia of Standards: Volume 29/24. Rockville, MD: The United States Pharmacopeial Convention; 2006:2617-2636.

48. Holt, J. (2009). The MMAD Calculator. Available from http://www. mmadcalculator.com/. Accessed September 20, 2012.

49. Tam JM, McConville JT, Williams RO 3rd, Johnston KP. Amorphous cyclosporin nanodispersions for enhanced pulmonary deposition and dissolution. J Pharm Sci. 2008;97(11):4915-4933.

50. Tandya A, Dehghani F, Foster NR. Micronization of cyclosporine using dense gas techniques. J Supercrit Fluids. 2006;37(3):272-278.

51. Katakai R, Iizuka Y. Conformation of oligopeptides with L-leucyl-Lleucyl-L-alanyl and L-methionyl-L-methionyl-L-leucyl repeating units. Biopolymers. 1984;23(7):1411-1422.

52. Piovesan Alves G, Santana MH. Phospholipid dry powders produced by spray drying processing: structural, thermodynamic and physical properties. Powder Technol. 2004;145(2):139-148.

53. Suarez S, Hickey AJ. Drug properties affecting aerosol behavior. Respir Care. 2000;45(6):652-666.

54. Dolovich M. Lung dose, distribution, and clinical response to therapeutic aerosols. Aerosol Sci Technol. 1993;18:230-240.

55. Andya JD, Maa YF, Costantino HR, et al. The effect of formulation excipients on protein stability and aerosol performance of spray-dried powders of a recombinant humanized anti-IgE monoclonal antibody. Pharm Res. 1999;16(3):350-358.

56. Sollohub K, Cal K. Spray drying technique: II. Current applications in pharmaceutical technology. J Pharm Sci. 2010;99(2):587-597.

57. Masters K. Spray Drying Handbook, 5th ed. New York, NY: John Wiley \& Sons; 1991.
International Journal of Nanomedicine

\section{Publish your work in this journal}

The International Journal of Nanomedicine is an international, peerreviewed journal focusing on the application of nanotechnology in diagnostics, therapeutics, and drug delivery systems throughout the biomedical field. This journal is indexed on PubMed Central,

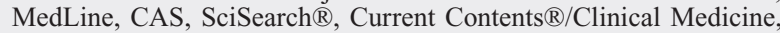

\section{Dovepress}

Journal Citation Reports/Science Edition, EMBase, Scopus and the Elsevier Bibliographic databases. The manuscript management system is completely online and includes a very quick and fair peer-review system, which is all easy to use. Visit http://www.dovepress.com/ testimonials.php to read real quotes from published authors. 